\title{
(6) \\ CRÍTICA ÀS METODOLOGIAS ATIVAS NA FORMAÇÃO PROFISSIONAL EM SERVIÇO SOCIAL
}

\author{
CRITICISM TO ACTIVE METHODOLOGIES IN VOCATIONAL TRAINING IN \\ SOCIAL WORK
}

\author{
Everton Melo da Silva* \\ http://orcid.org/0000-0002-2221-0936
}

\section{RESUMO}

Este artigo tem por objetivo problematizar, em uma perspectiva crítica, a relação entre os fundamentos das metodologias ativas e a formação profissional em Serviço Social. Através dos dados do INEP/2016 e do Censo EaD Brasil/2016, indicamos o crescimento das Instituições de Ensino Superior (IES) privadas no Brasil, apoiado no processo de mercadorização e transnacionalização da educação em tempos de crise do capital, neoliberalismo e contrarreforma do Estado, contribuindo para o aumento dos cursos e de matrículas em Serviço Social e para a entrada das metodologias ativas, com a finalidade de responder as demandas urgentes da racionalidade do mercado. Essa uniformização na nova forma de ensinar na formação profissional em Serviço Social propicia o imediatismo, o fortalecimento do pragmatismo profissional e provoca confusões teóricas sobre a relação entre teoria e prática, conforme observamos na análise de 05 Projetos Pedagógicos de Cursos (PPCs) de Serviço Social.

\section{PALAVRAS-CHAVE}

Ensino Superior. Formação profissional. Metodologias Ativas. Relação teoria e prática. Pragmatismo.

\begin{abstract}
This article aims to problematize, in a critical perspective, the relationship between the foundations of active methodologies and professional training in Social Work. Through data from INEP / 2016 and the Brazil / 2016 EaD Census, we indicate the growth of private higher education institutions (IES) in Brazil, supported by the process of commodification and transnationalization of education in times of capital crisis, neoliberalism and counterreformation Contributing to the increase of courses and enrollment in Social Service and to the entry of active methodologies, in order to respond to the urgent demands of market rationality. This uniformity in the new way of teaching in the professional formation in Social Service propitiates the immediatism, the strengthening of the professional pragmatism and causes theoretical confusions on the relation between theory and practice, as we observed in the analysis of 05 Teaching Projects of Social Work Courses (PPCs).
\end{abstract}

\section{KEYWORDS}

Higher education. Professional qualification. Active Methodologies. Relationship theory and practice. Pragmatism.

\footnotetext{
* Assistente social. Mestre em Serviço Social. Doutorando em Serviço Social pela UFAL. Bolsista CAPES. "O presente trabalho foi realizado com apoio da Coordenação de Aperfeiçoamento de Pessoal de Nível Superior - Brasil (CAPES) - Código de Financiamento 001. Endereço: Av. Lourival Melo Mota, S/N, Tabuleiro do Martins, Maceió (AL), Cep: 57072-970. Telefone: 079-999478322. E-mail: <evertonmsilva@outlook.com.br>.
}

DOI 10.22422/temporalis.2019v19n38p115-129

\section{(cc) Br} material em qualquer suporte ou formato, bem como adaptar, transformar e criar a partir deste material para qualquer fim, mesmo que comercial. O licenciante não pode revogar estes direitos desde que você respeite os termos da licença.

Temporalis, Brasília (DF), ano 19, n. 38, p. 147-161, jul./dez. 2019. | ISSN 2238-1856 


\section{INTRODUÇÃO}

$\mathrm{O}$ bjetivo deste artigo é proporcionar uma reflexão problematizadora sobre a adesão às metodologias ativas pelos cursos de Serviço Social no contexto exponencial de mercadorização do ensino superior brasileiro através de três hipóteses analíticas: 1. houve um crescimento do número de Instituições de Ensino Superior (IES) privadas durante os governos petistas (Lula e Dilma), e, consequentemente, aumento do número de cursos de Serviço Social em IES privadas, inclusive na modalidade de Ensino à Distância; 2. o ingresso em massa das metodologias ativas nas diversas formações profissionais responde as atuais demandas do mercado que exige profissionais mais imediatistas e generalistas práticos, que, na nossa avaliação, essas novas metodologias cumprem essa função, devido a sua natureza e características de ensino; e 3. com o aumento desmensurado de cursos de Serviço Social em IES privadas, esse curso não se esgueirou da nova lógica da forma de ensino e adere, em sua formação profissional, as metodologias ativas, o que implica reforço da dicotomização da teoria com a prática e, consequentemente, contribui para o pragmatismo profissional, e, consequentemente, transpassa rebatimentos desfavoráveis ao atual projeto profissional hegemônico do Serviço Social.

Para alcançar o objetivo ora proposto exploramos os dados do Censo do Ensino Superior do Instituto Nacional de Estudos e Pesquisas Educacionais Anísio Teixeira (INEP), do ano de 2016, e do Censo EAD (2016) da Associação Brasileira de Educação a Distância para mapear o cenário atual do Ensino Superior no Brasil e, particularmente, dos cursos de Serviço Social. Em seguida, examinamos a literatura sobre metodologias ativas, especialmente, os principais autores/pesquisadores dessa temática: Berbel (1995; 1998; 2012) e Moran (2015). Analisamos também 05 Projetos Pedagógicos de Cursos (PPCs) de Serviço Social que têm em sua forma de ensino as metodologias ativas. Esses cursos estão distribuídos nas seguintes IES privadas: Faculdade Projeção de Ceilândia (Distrito Federal), Faculdade Projeção Guará (Distrito Federal), Centro Universitário AGES (UniAGES/Bahia), Faculdade de Ciências e Tecnologia do Maranhão (FACEMA/Maranhão) e Faculdade Metropolitana da Amazônia (FAMAZ/Pará)'. Além disso, a análise contou com as reflexões de autores do Serviço Social sobre a relação teoria e prática e Serviço Social vinculados a perspectiva crítica marxiana.

\section{RACIONALIDADE DO MERCADO E MERCADORIZAÇÃO DO ENSINO SUPERIOR BRASILEIRO}

O Ensino Superior brasileiro foi transmutado em um negócio altamente rentável para o capital, onde as IES brasileiras se tornaram grandes empreendimentos mercadológicos. $O$ exemplo ilustrativo deste cenário é o oligopólio do Grupo Kroton Educacional S.A., que, em 2010, fez a maior aquisição no campo da educação superior do Brasil através da compra da IUNI Educacional (que dirige as marcas UNIC, UNIME e FAMA); em 2011, comprou a Faculdade Atenas Maranhese (Estado do Maranhão), a Faculdade União (Estado do

\footnotetext{
${ }^{1}$ Extraímos os dados dos PPCs através de um roteiro de pesquisa com quatro pergunta-chaves: qual a concepção de metodologias ativas postos nesses PPCs? Qual/quais metodologia(s) ativa(s) é/são utilizada(s) pela IES? Qual a/as justificativa/justificativas para a utilização das metodologias ativas? E como se expressa a relação teoria e prática e metodologias ativas nos PPCs?
}

Temporalis, Brasília (DF), ano 19, n. 38, p. 147-161, jul./dez. 2019. | ISSN 2238-1856 
Paraná), a Faculdade do Sorriso e a UNOPAR (uma das maiores companhias de Ensino à distância brasileira); em 2012, adquiriu o Centro Universitário Cândido Rondon e a UNIASSELVI; em 2013, fez acordo com a Anhanguera, tornando-se o maior grupo educacional do mundo; e, em 2016, tentou comprar a Universidade Estácio de Sá ${ }^{2}$ (o que seria a maior movimentação financeira no campo da educação privada), entretanto, o Conselho Administrativo de Defesa Econômica (CADE) reprovou a compra; além disso, em 2018, o Grupo Kroton Educacional comprou a SOMOS, dona das marcas Saraiva, Ática, Scipione, Anglo e a escola de idiomas Red Balloon³.

Este empreendimento educacional, que conta com investimentos de capital internacional (aquisição de ações), traz sérios riscos a formação profissional no Brasil, pois, revela a transnacionalização ${ }^{4}$ do ensino superior brasileiro, o crescimento do setor privado na educação e o domínio da formação guiada por um empreendimento de serviços educacionais através da determinação dos preços das mensalidades, controle privado na qualidade dos serviços, inexistência de concorrências de porte similar, comando do domínio do saber científico, além de influenciar na produção e divulgação do conhecimento, através da aquisição de grandes editoras. Outra problemática inquietante é a padronização da forma de ensinar e do que ensinar, visto que, "[...] o Grupo Educacional Kroton desenvolveu um modelo acadêmico único, denominado de Kroton Learning System (KLS)" (COSTA et al., 2017, p. 2, grifos do autor), caracterizado como um tipo de metodologia ativa5.

Neste horizonte favorável ao capital, vivemos em um solo complexo da formação profissional encoberto por diversos desafios e dificuldades, principalmente, perante duas razões substanciais: de um lado, com o crescente sucateamento das IES públicas, com a diminuição do orçamento destinado a educação (em 2018, a Lei Orçamentária Anual estimou que sejam gastos somente 4,52 bilhões com a educação, uma redução de $32 \%$ comparado ao ano anterior); em contrapartida temos a progressiva mercadorização da educação superior, onde o mercado tornou-se o principal agente e protagonista da formação profissional no Brasil, como podemos observar através do Grupo Kroton Educacional, classificada como a maior empresa de ensino privado do mundo controlada pelo capital financeiro internacional. Assim, a mercadorização da educação superior constitui-se transversalmente com "[...] expansão do ensino superior privado-mercantil

\footnotetext{
${ }^{2}$ Informações retiradas no site http://www.kroton.com.br/

3 Informações retiradas dos sites: https://www.valor.com.br/empresas/5860901/cade-aprova-compra-dasomos-e-kroton-passa-liderar-educacao-no-pais e https://oglobo.globo.com/economia/lider-em-ensinosuperior-kroton-compra-controle-da-somos-educacao-por-45-bilhoes-22619256

4 "A transnacionalização seria a oferta transfronteiriça de ensino, presencial ou a distância, por intermédio de organizações transnacionais de serviços educacionais com finalidade de lucro." (AZEVEDO, 2015, p. 87).

${ }^{5}$ Costa et. al (2017, p. 2, grifos do autor) situam que "[...] com o objetivo de atender a esses novos desafios da Educação Superior de se aproximar ao perfil da sociedade atual, o Grupo Educacional Kroton desenvolveu um modelo acadêmico único, denominado Kroton Learning System (KLS). Esse modelo está pautado em três grandes alicerces: promoção da empregabilidade dos alunos, foco em qualidade e inovação e oferta em escala (KROTON, 2014). [...] O modelo utiliza princípios da Sala de Aula Invertida, um tipo de metodologia ativa, que transforma o aluno de mero receptor de conhecimento a um ator envolvido e participante ativo no seu processo de ensino aprendizagem (CABERO, 2006). Além dos conteúdos trabalhados com os alunos por meio das atividades de pré-aula, aula e pós-aula, possibilita através das situações-problemas baseadas na rotina dos profissionais, o estímulo crítico e reflexivo, inserindo-os em ações reais e buscando soluções e aplicações para intervir na prática" (COSTA et al., 2017, p. 2, grifos do autor).
}

Temporalis, Brasília (DF), ano 19, n. 38, p. 147-161, jul./dez. 2019. | ISSN 2238-1856 
(for profit higher education), privatização direta, desresponsabilização do Estado, criação de quase-mercado, estabelecimento de Parcerias-Público-Privado (PPP), estímulo à competição, performatividade, rankings, indicadores etc. [...]” (AZEVEDO, 2015, p. 87, grifos originais).

Conforme apontam os últimos relatórios do INEP/MEC (INSTITUTO NACIONAL DE ESTUDOS E PESQUISAS EDUCACIONAIS ANÍSIO TEIXEIRA, 2016), com base no Censo do Ensino Superior, dispomos hoje da predominância de IES privadas em comparação com as IES públicas: em 2013, o número de IES totalizava 2.391, sendo 301 púbicas e 2.090 privadas; em 2014, tivemos 2.368 IES, 298 públicas e 2.070 privadas; e em 2015, contabilizou-se 2.364, sendo 295 públicas e 2.069 privadas. Isso significa que mais de $87 \%$ das IES brasileiras pertencem ao setor privado.

O boom da expansão do Ensino Superior no Brasil foi conduzido sob as bases do Programa de Apoio a Planos de Reestruturação e Expansão das Universidades Federais (Reuni), instituído pelo Decreto n. 6.096/2007, que previa a ampliação de vagas e cursos; do Programa Universidade para Todos (Prouni), criado a partir da Lei n. 11.096/2005, com a concessão de bolsas (integrais e parciais) em IES privadas, que em troca recebem isenções de impostos; e do Fundo de Financiamento Estudantil (Fies), estabelecido pela Lei n. $10.260 / 2001$, que o governo financia cursos para estudantes em IES privadas. Podemos somar ainda o Decreto n. 5.622/2005 e n. 9.057/2017 que regulam o Ensino à Distância.

Uma leitura aparente pode levar somente a conclusão de que esses programas e legislações garantiram a ampliação do acesso a educação superior (o que não deixa de ser verdade); porém, em larga medida, e compreendendo a relação de complementariedade entre Estado e mercado, o Prouni e o Fies, por exemplo, podem ser traduzidos no deslocamento do dinheiro público para o privado, através de isenções fiscais e destinação de recursos públicos para manutenção de empresas do setor educacional, obedecendo a lógica neoliberal à brasileira.

O crescimento do Grupo Kroton Educacional deve ser vinculado ao intervencionismo do Estado neoliberal que atua como fiador para o capital, implementando contrarreformas que favoreçam a manutenção do lucro dos capitalistas. Rememoramos que, em 2008, tivemos o aprofundamento da crise do capital que desencadeou fortemente no Brasil entre 2012 e 2013, período que a Kroton se tornou o maior empreendimento educacional com a compra da Anhanguera. Sem a complementação e impulsionamento do Estado brasileiro, este grupo não teria crescido em tempos de crise.

Em relação ao Reuni, alguns autores apontam que o governo federal ampliou as vagas e cursos sem dar condições de manutenção compatíveis com a ampliação, conforme explicita Koike (2009):

sem recursos assegurados, a expansão prevista pode sustentar-se à base de maior flexibilização e desregulamentação e a custa de aligeiramento do processo formativo e aumento da precarização do trabalho docente e técnicoadministrativo. A qualidade da formação e a produção de conhecimento estariam ameaçadas pelo "aulismo" em detrimento da pesquisa, pela falta de formação de pesquisadores e de intercâmbio desinteressado (sem estar submetido à lógica comercial/lucrativa) com a sociedade (KOIKE, 2009, p. 10). 
Entre os anos 2013-2015, houve uma evolução no número de matrículas no Ensino à Distância no Brasil: em 2013, tínhamos 1.153 .572 de matrículas, que correspondia a 15,79\% comparada a modalidade presencial; em 2014, esse quantitativo cresceu para 1.341 .842 (17,14\%); e, em 2015, esse número subiu para 1.393.752 (17,36\%) (INSTITUTO NACIONAL DE ESTUDOS E PESQUISAS EDUCACIONAIS ANÍSIO TEIXEIRA, 2016), o que revela o crescimento desta modalidade de ensino na oferta de serviços educacionais para o Ensino Superior. A adesão ao Ensino à Distância não foi gestada de forma aleatória, esta modalidade de ensino tem se manifestado como uma "[...] estratégia de expansão lucrativa [...]” (PEREIRA, 2018, p. 189) para o capital. A retórica da democratização do acesso à educação superior foi a principal linha argumentativa dos setores que defendiam/defendem essa modalidade de ensino, o que pode ser traduzido em "[...] massificação como democratização do acesso [...]" (KOIKE, 2009, p. 19).

Ao particularizar a formação profissional em Serviço Social, verificamos que nos últimos anos houve um alargamento exponencial da oferta de cursos dessa profissão no Brasil. 0 curso de Serviço Social ocupou a $9^{\text {a }}$ posição como maior curso do Brasil com mais de 172 mil matrículas em 2015, com 90\% do curso ingressado pelo sexo feminino (INSTITUTO NACIONAL DE ESTUDOS E PESQUISAS EDUCACIONAIS ANÍSIO TEIXEIRA, 2016), e é o $3^{\circ}$ mais procurado pelo Ensino à distância, segundo o Censo EAD Brasil (2016), ficando a Pedagogia e Administração em $1^{\circ}$ e $2^{\circ}$ lugares, respectivamente.

Os dados do Censo de Educação Superior 2016 revelam que o curso de Serviço Social é ofertado em 348 IES brasileiras, das quais 83,05\% (289) são privadas, enquanto apenas 16,95\% (59) são públicas. Ou seja, temos a maioria dos assistentes sociais formados pela lógica mercadológica da educação em detrimento da pública. Na modalidade a distância, este curso é ofertado em 28 instituições, o que corresponde a um percentual de $8,05 \%$ do total de IES quando comparado ao ensino presencial. E, dentre as 28 instituições que ofertam Serviço Social na modalidade EaD, 27 (96,43\%) pertencem ao setor privado e apenas 1 (3,57\%) pertence ao setor público (INSTITUTO NACIONAL DE ESTUDOS E PESQUISAS EDUCACIONAIS ANÍSIO TEIXEIRA, 2016).

Quanto ao quantitativo de matrículas, os dados do INEP expõem que, no ensino presencial em Serviço social registrou-se um total de 164.691 matrículas, sendo 144.580 (87,79\%) na rede privada e 20.111 (12,21\%) na rede pública, descortinando a secundarização do ensino público na formação profissional em Serviço Social. Na modalidade do Ensino à Distância no Serviço Social, o número de matrículas, em 2016, foi de 96.055 , das quais 93.827 (97,68\%) na rede privada e 2.228 (2,32\%) na rede pública (INSTITUTO NACIONAL DE ESTUDOS E PESQUISAS EDUCACIONAIS ANÍSIO TEIXEIRA, 2016).

Esses números sobre os cursos de Serviço Social são, no mínimo, preocupantes porque traz uma série de rebatimentos para a profissão, conforme alertou lamamoto (2011):

[...] o crescimento exponencial do contingente profissional, a curto prazo, traz sérias implicações para o exercício profissional e para as relações de trabalho e condições salariais por meio das quais se realiza. Pode-se antever um crescimento acelerado do desemprego nessa área, pois dificilmente a oferta de postos de trabalho poderá acompanhar, no mesmo ritmo, o crescimento do contingente profissional, pressionando o piso salarial, a precarização das condições de trabalho e aumentando a insegurança do trabalho. A hipótese que se pode 
aventar é que o crescimento do contingente profissional, ao tempo que eleva a lucratividade nos negócios educacionais -, um curso barato, voltado predominantemente ao público feminino -, poderá desdobrar-se na criação de um exército assistencial de reserva IAMAMOTO, 2011, p. 40).

Essa expansão desmensurada da profissão ${ }^{6}$ acompanha a (des)configuração da imagem da profissão, mudança no projeto profissional crítico e imprecisões sobre as noções de competências e habilidades.

A incessante lógica lucrativa educacional tem impulsionado também as tentativas de oferta de cursos de Serviço Social na modalidade de cursos de extensão por IES privadas, casos notificados na Bahia, Rio Grande do Norte e Ceará, que não foram autorizados pelo Ministério da Educação (MEC). Segundo o Parecer do CRESS-RN, de 06 de março de 2017, "[...] a oferta de curso de extensão com promessa de aproveitamento de disciplinas obrigatórias para a modalidade de graduação, configura-se oferta irregular do curso de graduação em Serviço Social [...]" (CONSELHO REGIONAL DE SERVIÇO SOCIAL, 2017). Inclusive o CFESS aprovou uma resolução (CFESS N ${ }^{\circ}$ 755, de 27 de abril de 2016) sobre os pedidos de inscrição profissional provenientes (direta ou indiretamente) de cursos de Serviço Social ofertados através de cursos livres de extensão.

Desse modo, é perceptível que o mercado comanda o serviço de educação superior no Brasil, além de ditar regras da formação profissional, exige formações cada vez mais fragmentadas, aligeiradas e imediatas, sem qualquer preocupação com os projetos profissionais vigentes.

No processo crescente de mercantilização do Ensino Superior no Brasil, as IES privadas competem entre si, e, para captar maiores parcelas de mercado, devem dispor, na lógica de atrativos básicos, de, por exemplo, uma excelente infraestrutura, capacidade de inovação e alto nível tecnológico, aliados as estratégias de marketing para dar visibilidade ao mercado e a sociedade (clientes). Além disso, com o avanço das tecnologias da informação e comunicação (TIC's) nas últimas décadas, as IES privadas se diferenciam à medida que investem nesse setor.

O capital exige que as IES formem profissionais em ritmo frenético para atender as demandas do mercado, e que seus currículos estejam sempre adaptados as suas demandas. Koike (2009) afirma que, “[...] o processo de adequação do sistema educacional às necessidades de resposta do capital à sua crise contemporânea se desenrola por dentro da contrarreforma do Estado" (KOIKE, 2009, p. 6). A predicação do mercado de trabalho tem versado sobre uma formação profissional mais prática e mais dinâmica, com resoluções rápidas de casos concretos, com conteúdo mais técnico interventivo emenos abstrato.

Logo, o clamor do mercado, que é altamente competitivo e tem urgência de lucros, é por formações cada vez mais técnicas e rápidas e que respondam de forma imediata a

\footnotetext{
${ }^{6} \mathrm{O}$ alerta que lamamoto (2011) fez sobre o crescimento de um exército assistencial de reserva é mais atual e preocupante do que nós imaginamos. Em um texto mais recente, ela afirma que: "[...] o contingente de assistentes sociais brasileiros é o segundo no cenário mundial, com 160 mil profissionais ativos, conforme dados do Conselho Federal de Serviço Social (CFESS), apenas superado pelos Estados Unidos. Na América Latina, a International Federation of Social Workers (IFSW) estima um total de 200 mil profissionais congregados em onze associações nacionais. Na Europa, são 170 mil assistentes sociais em 35 países" (IAMAMOTO, 2017, p. 19-20).
}

Temporalis, Brasília (DF), ano 19, n. 38, p. 147-161, jul./dez. 2019. | ISSN 2238-1856 


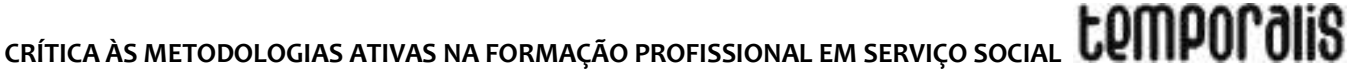

realidade, o que acarreta, de forma direta e/ou indireta, numa reconfiguração da formação profissional para se adequar a esta realidade, seja através do aligeiramento da formação, da valoração da técnica (tecnicismo) ou de inovações de metodologias de ensino que respondam de forma imediata essa realidade, como é o caso das metodologias ativas.

Neste percurso de inovações ideológicas e educacionais e adicionando a lógica mercadológica da educação superior, as metodologias ativas têm sido reveladas como um prato cheio para a racionalidade do mercado, visto que a mesma assegura, indiretamente, que sua forma de ensino corresponde as demandas reais da sociedade (mercado), assegura uma formação profissional mais prática e técnica em detrimento do teoricismo acadêmico, que fica subjugado em segundo plano.

\section{METODOLOGIAS ATIVAS NA FORMAÇÃO PROFISSIONAL DO SERVIÇO SOCIAL}

As metodologias ativas têm como principal fundamento, independentemente de suas variações e traços constitutivos, a centralidade do saber no aluno, que é visto como o principal agente na relação ensino-aprendizagem, sujeito que deve ser ativo no processo de produção e reprodução do conhecimento, diferentemente da metodologia tradicional que centra no docente, na transmissão de conteúdo (BERBEL, 1995; 1998, 2012; DIESEL; BALDEZ; MARTINS, 2017). Por exemplo, a sala de aula invertida, que se constitui como um tipo de metodologia ativa, pauta que o aluno deve estudar em casa e levar para sala de aula os questionamentos e as dúvidas, diminuindo a participação/exposição do professor. Esse tipo de metodologia nos lembra a modalidade EaD, onde o aluno estuda os conteúdos (lê textos e assiste videoaulas) e leva as dúvidas para os encontros presenciais ou para os meios virtuais de comunicação (fóruns, sala de bate-papo ou chats).

A maioria dos PPCs dos cursos de Serviço Social que aderiram as metodologias ativas analisados não conceitua metodologia ativa, apenas o PPC da UniAGES (2016c, p. 26) aponta que "[...] o Ensino UniAGES possui como centro de sua proposta de ensino as metodologias ativas como propostas que colocam os estudantes no centro do processo e o docente como o sujeito que cuida da aprendizagem deles [...]" , coadunando com o principal princípio das metodologias ativas: a centralidade no aluno (BERBEL, 1995, 1998, 2012). Além disso, esse dado revela que os PPCs desses cursos não tiveram a preocupação de apresentar conceituações teóricas sobre metodologias ativas.

Teóricos das metodologias ativas (ou do método ativo) criticam a educação formal e o ensino tradicional, alegam, o que pode ser verdade em alguma medida, que aquele tipo de educação não corresponde mais a realidade, que não atende mais aos anseios do mercado. Para Moran (2015), "[...] a escola padronizada, que ensina e avalia a todos de forma igual e exige resultados previsíveis, ignora que a sociedade do conhecimento é baseada em competências cognitivas, pessoais e sociais, que não se adquirem da forma convencional e que exigem proatividade, colaboração, personalização e visão empreendedora" (MORAN, 2015, p. 16).

\footnotetext{
7 Conforme podemos observar no PPC de Serviço social da FACEMA (2009, p. 5): “[...] nesta proposta, o processo ensino-aprendizagem não está voltado para a definição e reprodução de conteúdos julgados relevantes, mas para a construção das habilidades e competências necessárias à formação do profissional do Serviço Social, oferecendo metodologias dinâmicas, inovadoras e atualizadas sempre preocupadas com inserção e adaptação desses profissionais na comunidade residente."
}

Temporalis, Brasília (DF), ano 19, n. 38, p. 147-161, jul./dez. 2019. | ISSN 2238-1856 
A tese da sociedade do conhecimento surgiu como oposição a tese da sociedade do trabalho nas últimas décadas, fruto da ascensão do irracionalismo e relativismo próprios da pósmodernidade. Esta nova sociedade que surge, para os teóricos das metodologias ativas, demanda uma nova forma de ensinar que valorize o indivíduo, o aluno, e que esse aprenda fazendo, como podemos observar com Moran (2015): “[...] a combinação de aprendizagem por desafios, problemas reais, jogos, com a aula invertida é muito importante para que os alunos aprendam fazendo, aprendam juntos e aprendam, também, no seu próprio ritmo" (MORAN, 2015, p. 22-23). Esse aprender fazendo pode ser compreendido como um praticismo sem mediação teórica.

Se por um lado o aprender fazendo se distancia da relação entre teoria e prática posta pelo pensamento marxiano, não podemos reduzir a formação ao como fazer:

[...] o que tem gerado um limitado trato do 'como' utilizar os instrumentos e das habilidades necessárias ao seu manuseio, fortalecendo uma valorização unilateral da dimensão teórico-política da intervenção profissional, sob a alegação de que um bom ensino teórico é suficiente para se apreender, distinguir e habilitar os estudantes a utilizarem os instrumentos e técnicas necessárias à intervenção profissional. Como já observado, essa concepção reforça a acusação da categoria profissional de que a direção teórica marxista não se viu acompanhar de um arsenal de instrumentos e técnicas próprios (SANTOS, 2006, p. 170).

À primeira vista, o clamor por cenários de práticas é interessante, porém, notamos que o campo das práticas sobrepõe-se a teoria; o praticismo, aqui compreendido como "[...] ação prático-utilitária visando a fins imediatos sem as mediações de análises de caráter históricosocial nos processos de intervenção social e política [...]" (SANTOS, 2011, p. 157), assume centralidade em detrimento das mediações teóricas; onde deveria haver o fortalecimento da relação teoria e prática, há a exaltação dessa sobre aquela, conforme aponta Abreu (2009 apud DIESEL; BALDEZ; MARTINS, 2017, p. 273, grifos nossos): “[...] ao contrário do método tradicional, que primeiro apresenta a teoria e dela parte, o método ativo busca a prática e dela parte para a teoria" . Assim, onde deveria haver relação teoria e prática, tomando-a como uma unidade (não podendo ser confundida com identidade), há sobreposição de uma sobre a outra, há separação entre teoria e prática.

Moran (2015, p. 21, grifos originais) situa alguns tipos de metodologias ativas comuns no Ensino Superior:

O Peer Instruction é uma das metodologias inovadoras aplicadas por professores nos diversos cursos. Outros métodos utilizados são PBL - Project Based Learning (aprendizagem por meio de projetos ou de problemas); TBL -Team-based Learning (aprendizagem por times), WAC - Writing Across the Curriculum (escrita por meio das disciplinas) e Study Case (estudo de caso) ${ }^{8}$ (MORAN, 2015, p. 21, grifos do autor).

No que concerne aos tipos de metodologias ativas utilizadas pelos cursos de Serviço Social identificamos as seguintes: a Instrução por Colegas ou a Peer Instruction (Faculdade Projeção Ceilândia e Guará); metodologia da problematização (FACEMA); Pedagogia de

\footnotetext{
${ }^{8}$ Temos ainda a Sala invertida e Estilo de aprendizagem e Método Ciclo de Aprendizagem Vivencial (CAV), entre outras.
}

Temporalis, Brasília (DF), ano 19, n. 38, p. 147-161, jul./dez. 2019. | ISSN 2238-1856 


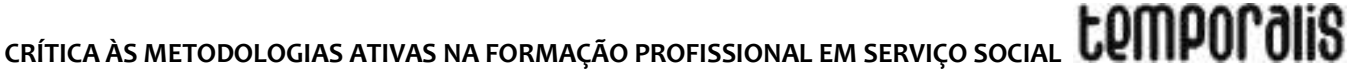

Projetos ou Project Based Learning, aprendizagem autodirigida e aprendizagem baseada em problemas ou casos (FAMAZ); e Método do Arco de Maguerez (UniAGES).

Na análise de Dácio (2014, p. 2), as metodologias ativas possuem as seguintes características:

\begin{abstract}
1. Demandam e estimulam a participação do aluno envolvendo-o em todas as suas dimensões humanas: sensório-motor, afetivo-emocional, mental-cognitiva. 2. Respeitam e estimulam a liberdade de escolha do aluno diante dos estudos e atividades a serem desenvolvidas, possibilitando a consideração de múltiplos interesses e objetivos. 3. Valorizam e se apoiam na contextualização do conhecimento, imprimindo um sentido de realidade e utilidade nos estudos e atividades desenvolvidas. 4. Estimulam as atividades em grupos, possibilitando as contribuições formativas do trabalho em equipe. 5. Promovem a utilização de múltiplos recursos culturais, científicos, tecnológicos que podem ser providenciados pelos próprios alunos no mundo em que vivemos. 6. Promovem a competência de socialização do conhecimento e dos resultados obtidos nas atividades desenvolvidas (DÁCIO, 2014, p. 2).
\end{abstract}

O ponto medular dessas características é a centralidade no sujeito, enquanto indivíduo tomado somente em sua singularidade, no processo de ensino-aprendizagem, e a ausência de ponderações sobre os fatores objetivos essenciais para o aprendizado do aluno, como podemos observar no PPC do curso de Serviço Social da UniAGES (2016, p. 24): “[...] o aluno é agente ativo, comprometido, responsável, capaz de planejar suas ações, assumir responsabilidades, tomar atitudes diante dos fatos e interagir no meio em que vive, contribuindo, desta forma, para a melhoria do processo ensino-aprendizagem." Essa centralidade no aluno

[...] coloca em relevo o sujeito individual na condição de ser racional, protagonista da ação, da qual decorre sua convicção na articulação entre razão e experiência. O que vai resultar numa determinada maneira de conceber a relação teoria/prática em que pesem as condições causais impostas, servindo o pensamento para permitir que o sujeito proceda à sua própria adaptação (GUERRA, 2013, p. 5).

As metodologias ativas também mudam o papel do professor no processo de ensinoaprendizagem: transforma-o em orientador e curador: "[...] curador, no sentido também de cuidador: ele cuida de cada um, dá apoio, acolhe, estimula, valoriza, orienta e inspira. Orienta a classe, os grupos e a cada aluno [...]" (MORAN, 2015, p. 24); responsabiliza-o pela tarefa hercúlea de inovador e estimulador dos alunos. Além disso, nas IES privadas, o professor obrigatoriamente deve seguir a metodologia ativa imposta, excluindo qualquer possibilidade de autonomia da forma de ensinar. Diesel, Baldez e Martins (2017, p. 271) defendem que "[...] método ativo é um processo que visa estimular a autoaprendizagem e a curiosidade do estudante para pesquisar, refletir e analisar possíveis situações para a tomada de decisão, sendo o professor apenas o facilitador desse processo (BASTOS, 2006 apud BERBEL, 2011)".

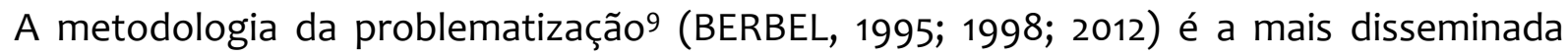
atualmente, pois é considerada "[...] como uma alternativa metodológica com grande

9 De acordo com Berbel (1995), a metodologia da problematização foi proposta por Charlez Maguerez (Método do Arco), e Bordenave e Pereira que trazem para o Brasil em 1977.

Temporalis, Brasília (DF), ano 19, n. 38, p. 147-161, jul./dez. 2019. | ISSN 2238-1856 
potencial pedagógico para preparar o futuro profissional e cidadão, requerido para uma sociedade em rápidas transformações" (BEBERL, 1995, p. 9). Essas rápidas transformações são decorrentes da eclosão da crise estrutural do capital, no final dos anos 1970, que exige mudanças na forma de intervenção do Estado e na produção e organização do trabalho.

Segundo Berbel (1995), essa metodologia possui as seguintes etapas: observação da realidade e definiçãa de um problema de estudo, pontos-chaves, teorização, hipóteses de solução e aplicação à realidade. A autora elucida cada etapa: Observação da realidade: "[...] é o início de um processo de apropriação de informações pelos alunos" (BERBEL, 1995, p. 14); pontos-chaves: "[...] podem ser expressos através de questões básicas que se apresentam para o estudo [...]" (BERBEL, 1995, p. 15); teorização: apresentação de conceito de alguns autores que discutem uma determinada temática; hipóteses de solução: “[...] esta é uma etapa em que a criatividade e a originalidade devem ser bastante estimuladas. Se os procedimentos comuns, se os padrões já conhecidos permitem a existência do problema, é preciso pensar e agir de modo inovador, para provocar a sua superação (ou solução)" (BERBEL, 1995, p. 15); e aplicação à realidade: “[...] esta etapa é destinada à prática dos alunos na realidade social. É a fase que possibilita o intervir, o exercitar, o manejar situações associadas à solução do problema" (BERBEL, 1995, p. 16).

Berbel (1995) pontua que aqueles passos citados anteriormente são importantes por "[...] garantir alguma forma de aplicação real do estudo no contexto a partir do qual teve origem o problema" (BERBEL, 1995, p. 16). Guerra (2013) subsidia nossa análise sobre a relação entre a teoria e a sua "aplicabilidade" na prática ao apontar o consequencialismo como um dos núcleos do pragmatismo ao dialogar com Dewey:

\footnotetext{
Para ele, a relevância do conhecimento constitui-se à medida que serve de instrumento para a resolução de problemas. O que importa na relação teoriaprática para o pragmatismo não é a relação entre teoria e realidade, senão que as formulações teóricas se constituam em guia para a investigação. Assim, tais formulações teóricas são válidas à medida que tenham utilidade e êxito na investigação da realidade na qual o sujeito insere-se. Desse modo, não interessa que a teoria seja a expressão mais próxima possível da realidade, mas que sirva como orientação para testar se as concepções teóricas relacionam-se de fato com a experiência do sujeito, daí extraindo a veracidade das mesmas (GUERRA, 2013, p. 5).
}

Berbel (1995; 1998; 2012), que utiliza esta metodologia desde 1992, afirma inspiração na tradição marxista ao respaldar seus estudos em Adolfo Sanchez Vasquez, Paulo Freire e Dermeval Saviani, porém, na nossa análise, a autora pode se configurar como um exemplo da relação entre pragmatismo e marxismo (GUERRA, 2013), devido ao seu entendimento equivocado da aplicabilidade da teoria, como podemos observar também através do parágrafo abaixo:

Aplicação prática à realidade. Nessa etapa, devem ser analisadas e escolhidas as propostas de soluções mais viáveis, que poderão ser postas em prática e ajudarão a superar o problema no todo ou em parte, contribuindo para a transformação da realidade investigada. [...] Permite que o aluno aplique o conhecimento adquirido ao meio estudado, percebendo-se como sujeito ativo e exercendo a sua cidadania. (VILLARDI; CYRINO; BERBEL, 2015, p. 48, grifos dos autores). 
Para Santos (2006, p. 41) a defesa de “[...] aplicação da teoria à prática [...]” sai do campo teórico marxiano, pois, "[...] é preciso passar da atividade teórica à prática, mas, de per si, a teoria não pode dar esse passo, não se passa direta e imediatamente de uma esfera à outra" (SANTOS, 2006, p. 41).

O interesse inicial em problematizar a relação entre metodologias ativas e a formação profissional em Serviço Social decorreu fundamentalmente da assertiva de aplicabilidade da teoria na prática, defendida por essa nova forma de ensino, que, na nossa análise desconfigura o projeto profissional hegemônico e reforça o pragmatismo profissional. Devemos mediatizar que o Serviço Social é vulnerável ao pragmatismo devido sua natureza interventiva:

[...] as profissões 'interventivas' ou 'aplicadas', pela condição na qual se inserem na realidade, em geral, restringem a verdade aos conceitos que podem ser aplicados nas situações do cotidiano. Também no Serviço Social, esta concepção de que a verdade está nas consequências alcançadas como resultado da instrumentalidade dos sujeitos, isto é, da sua capacidade de solucionar situações prático-imediatas, tem sido recorrente (GUERRA, 2013, p. 6).

No cenário de esfacelamento da educação superior, os ataques ao processo formativo do Serviço Social se tornaram recorrentes através de diversas tentativas de aceleração da formação, reducionismo dos conteúdos-chave das Diretrizes Curriculares (temos o exemplo da versão das Diretrizes Curriculares aprovada pelo MEC em 2002), depreciação com a importância do estágio supervisionado etc., o que levam a fragilização dos princípios e valores que norteiam o projeto profissional. Uma nova preocupação posta pela realidade é a vinculação entre a mercadorização do Ensino Superior e a uniformização da forma de ensinar com as metodologias ativas, que traz sérios rebatimentos para a formação profissional em Serviço Social, conforme argumentado até o momento.

A vinculação entre metodologias ativas e formação profissional em Serviço Social traz dados inquietantes sobre a relação entre teoria e prática nos PPCs analisados, conforme apresentamos abaixo:

Pode-se extrair deste contexto que os Cursos Superiores da Faculdade Projeção do Guará em suas concepções curriculares, privilegiam o saber em articulação com a prática que oferecem as organizações e empresas, reconhecendo que estas desempenham um papel importante no desenvolvimento, na inovação e na produção de bens e serviços. E, sobretudo, privilegia a aprendizagem ativa e significativa, por meio da centralidade do aluno no processo de ensino e aprendizagem (PPC, Faculdade Projeção Ceilândia e Guará, 2016, p. 12, grifos nossos).

O modelo de currículo é o integrado que prevê a articulação, de forma dinâmica, da teoria e prática, por meio da integração dos conteúdos e abordagem de temas transversais como ética, cidadania, solidariedade, justiça social, inclusão e exclusão social, ecologia, cultura e outros, tendo como eixo estruturante os objetivos, o perfil do egresso e as competências gerais e específicas apresentados neste Projeto Pedagógico. Esta modalidade curricular requer a adoção da metodologia ativa e da problematização [...] (PPC, FACEMA, 2009, p. 28, grifos nossos). 
O Curso de Bacharelado em Serviço Social parte da premissa epistemológica de que o conhecimento se produz através de um processo de aprendizado contínuo e aberto a inúmeras contingências e só pode ser compreendido através da indissociável vinculação entre teoria e prática e entre os diversos saberes que compõem a estrutura curricular do curso, que está comprometida com o desenvolvimento do espírito científico e com a formação de sujeitos críticos, autônomos e cidadãos (PPC, FAMAZ, 2017, p. 37, grifos nossos).

Assim, as práticas da técnica de problematização em disciplinas e projetos especiais e o aprofundamento teórico vivido no currículo dos cursos existentes na instituição AGES foram os alicerces para a construção da ideia a fim de se discutir um currículo inovador para o curso de Serviço Social que pudesse contemplar a valorização do conhecimento prévio do estudante, a consideração da realidade como ponto de partida para a construção dos conhecimentos, das habilidades e atitudes, e o estímulo à busca de soluções dos problemas da prática de ensino/aprendizagem e a concepção de que não existe dicotomia entre teoria $e$ prática, elas são intrínsecas (PPC, UNIAGES, 2016, p. 38, grifos nossos).

Parece-nos razoável afirmar que os PPCs, em alguma medida, preocupam-se com a relação entre teoria e prática ao afirmarem que não existe dicotomia entre teoria e prática e defenderem a vinculação ou articulação entre esses dois polos. Entretanto, a preocupação que emerge é: qual o real entendimento sobre a relação entre teoria e prática desses PPCs? Pois, se estivermos corretos em nossa análise, as metodologias ativas e a relação teoria e prática, apoiado na teoria social marxiana, excluem-se devido ao antagonismo dos seus fundamentos.

O projeto hegemônico profissional do Serviço Social brasileiro compreende a relação entre teoria e prática a partir dos fundamentos ontológicos marxiano, pautados na centralidade do trabalho, no vínculo de determinação entre objetividade e subjetividade. Sobre a relação entre teoria e prática, as elaborações de Santos (2006) são fundamentais neste momento:

\begin{abstract}
Teoria é a apreensão das determinações que constituem o concreto e prática é o processo de constituição desse concreto; teoria é a forma de atingir, pelo pensamento, a totalidade, é a expressão do universal, ao mesmo tempo que culmina no singular e no universal. É através da teoria que se pode desvendar a importância e o significado da prática social, ou seja, ela é o movimento pelo qual o singular atinge o universal e deste volta ao singular. A prática é constitutiva e constituinte das determinações do objeto; gera produtos que constituem o mundo real; não se confunde, portanto, com a teoria, mas pode ser o espaço de sua elaboração. Nesse caso, ela só se transforma em teoria se o sujeito refleti-la teoricamente (SANTOS, 2006, p. 35).
\end{abstract}

A metodologia ativa centra o processo de ensino-aprendizagem no aluno, tomando-o como sujeito singular, defende uma aplicabilidade da teoria sobre a prática e revela que só tem validade um conhecimento se proporcionar uma intervenção na realidade, solucionar os problemas.

Ao apontar a crítica a essa forma de ensino, compreendemos essas metodologias ativas como uma proposta de reforço do pragmatismo que exclui as mediações (categoria central no processo interventivo do assistente social), pois, assimilamos, a partir de Santos (2006), que: "[...] nem a teoria se transforma em prática nem a prática se transforma em teoria" (SANTOS, 2006, p. 230). E, reforçamos com Guerra (2013) que "[...] a abstração das 


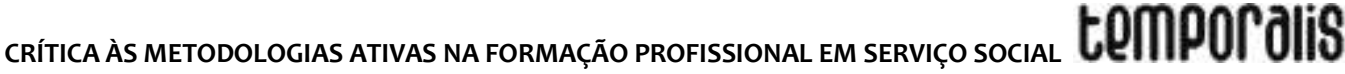

mediações como resultado de uma apreensão da realidade na sua imediaticidade é o procedimento da consciência comum, própria do cotidiano, que não questiona a gênese e não alcança a apreensão dos fundamentos" (GUERRA, 2013, p. 3).

\section{CONSIDERAÇÕES FINAIS}

Após problematizar essas vinculações entre a formação profissional em Serviço Social e os fundamentos das metodologias ativas, podemos razoavelmente retirar algumas conclusões: 1. Existe uma adesão as metodologias ativas de forma "involuntária" por cursos de Serviço Social, a partir de tensionamentos com a lógica das IES privadas que padronizam forma de ensinar para todos os cursos; 2. A adesão pelos cursos está sendo realizada de forma descuidada, sem travar debates teórico-metodológicos e/ou pesquisar sobre os impactos das metodologias ativas no projeto de formação profissional hegemônico, conforme visualizamos nos PPCs; 3. E, há algumas tentativas de relacionar fundamentalmente a teoria social marxiana com os princípios das metodologias ativas, que, na nossa avaliação, há uma incompatibilidade entre elas.

Ponderamos que as metodologias ativas devem fazer parte da listagem de preocupações dos diversos sujeitos (discentes, docentes, profissionais de campo e pesquisadores) que compõem o Serviço social e preocupam-se com o projeto profissional, pois, ao passo que sinalizamos ao longo do texto, temos expressões atuais de cursos que aderem essa forma de ensino sem fazer as devidas problematizações, que, obviamente essa forma de ensino sem fazer as devidas problematizações, que, obviamente, irá rebater na atuação profissional e a forma de atendimentos das demandas profissionais.

\section{REFERÊNCIAS}

ASSOCIAÇÃO BRASILEIRA DE EDUCAÇÃO A DISTÂNCIA. Censo EaD/BR: relatório analítico da aprendizagem a distância no Brasil. Curitiba: InterSaberes, 2017. Disponível em: http://abed.org.br/censoead2016/Censo_EAD_2016_portugues.pdf. Acesso em: 20 out. 2018.

AZEVEDO, Mário Luiz Neves de. Transnacionalização e mercadorização da educação superior: examinando alguns efeitos colaterais do capitalismo acadêmico (sem riscos) no Brasil - A expansão privado-mercantil. Revista Internacional de Educação Superior, Campinas, v. 1, n. 1, p. 86-102, 2015. Disponível em: https://periodicos.sbu.unicamp.br/ojs/index.php/riesup/article/view/8650522. Acesso em: 20 out. 2018.

BERBEL, Neusi Aparecida Navas. A metodologia da problematização em três versões no contexto da didática e da formação de professores. Revista Diálogo Educacional, Curitiba, v. 12, n.35, p. 103-120, jan./abr. 2012.

BERBEL, Neusi Aparecida Navas. A problematização e a aprendizagem baseada em problemas: diferentes termos ou diferentes caminhos? Interface - Comunicação, Saúde, Educação, v.2, n.2, 1998. 
BERBEL, Neusi Aparecida Navas. Metodologia da Problematização: uma alternativa metodológica apropriada para o Ensino Superior. Semina: Ciências Sociais e Humanas, Londrina, v.16. n. 2., Ed. Especial, p.9-19, out. 1995.

BERBEL, Neusi. As metodologias ativas e a promoção da autonomia dos estudantes. Semina: Ciências Sociais e Humanas, Londrina, v. 32 , n. 1 , p. 2540 , jan./jun. 2011. CONSELHO FEDERAL DE SERVIÇO SOCIAL. Resolução Nº 755, de 27 de abril de 2016. Brasília (DF), 2016. Disponível em: http://www.cfess.org.br/arquivos/ResCfess7552016.pdf. Acesso em: 10 nov. 2018.

CONSELHO REGIONAL DE SERVIÇO SOCIAL. Parecer sobre aspectos relacionados aos Cursos de nível superior de Serviço Social que estão sendo oferecidos na modalidade de Curso de Extensão. Natal, 2017. Disponível em:

http://www.cressrn.org.br/app/webroot/upload/files/PARECER\%20DA\%20COFI\%20SOBRE\% 20CURSOS\%20DE\%20EXTENS\%C3\%83O\%281\%29.pdf. Acesso em: 10 nov. 2018.

COSTA, Daniele Bernardi da; FREITAS, Franciely Midori Bueno de; KORZUNE, Lia Juliane; TOMEDI, Danieli Juliani Garbuio; KLAUS, Melina. Kroton Learning System 2.0: modelo acadêmico utilizado em um curso de graduação em Enfermagem à distância (relato de experiências). Londrina, PR: 2017. Disponível em:

http://www.abed.org.br/congress02017/trabalhos/pdf/372.pdf. Acesso em: 03 nov. 2018.

DÁCIO, Guimarães de Moura. Metodologias ativas de aprendizagem e os desafios educacionais da atualidade. Palestra. In: ENCONTRO NACIONAL DE DIRIGENTES DE GRADUAÇÃO DAS IES PARTICULARES, 11., Curitiba, 2014. Anais [...]. Curitiba-PR: Universidade Positivo, 11 set. 2014.

DIESEL, Aline; BALDEZ, Alda Leila Santos; MARTINS, Silvana Neumann. Os princípios das metodologias ativas de ensino: uma abordagem teórica. Revista Thema. Ciências Humanas, v. 14, n. 1, p. 268-288, 2017.

GUERRA, Yolanda. Expressões do pragmatismo no Serviço Social: reflexões preliminares. Revista katálysis, Florianópolis, v. 16, n. esp., p. 39-49, 2013.

IAMAMOTO, Marilda Villela. 80 anos do Serviço Social no Brasil: a certeza na frente, a história na mão. Serviço Social e Sociedade, São Paulo: Cortez, n. 128, jan. abr,/2017, p.1338.

IAMAMOTO, Marilda Villela. Serviço Social em Tempo de Capital Fetiche: capital financeiro, trabalho e questão social. São Paulo: Cortez, 2011.

INSTITUTO NACIONAL DE ESTUDOS E PESQUISAS EDUCACIONAIS ANÍSIO TEIXEIRA. Sinopse Estatística da Educação Superior 2016. Brasília (DF), 2017.

Disponível em: http://portal.inep.gov.br/basica-censo-escolar-sinopse-sinopse. Acesso em: 04 nov. 2018.

KOIKE, Maria Marieta. Formação Profissional em Serviço Social: exigências atuais. In: Serviço Social: Direitos Sociais e Competências Profissionais. Brasília (DF): CFESS; ABEPSS, 2009. 


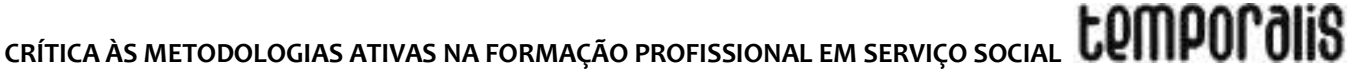

MORAN, José. Mudando a educação com metodologias ativas. SOUZA, Carlos Alberto de.; MORALES, Ofeliz Elisa Torres (Orgs.). Convergências Midiáticas, Educação e Cidadania: aproximações jovens. PG: Foca Foto-PROEX/UEPG, 2015.

PEREIRA, Larissa Dahmer. Expansão dos cursos públicos de Serviço Social entre os anos de 2003 e 2016: desafios para a formação profissional. R. Katálysis., Florianópolis, v. 21, n. 1, p. 189-199, jan./abr. 2018.

PPC. Projeto Pedagógico do curso de Serviço Social. Faculdade Projeção de Ceilância. Ceilândia (DF), 2016a. Disponível em:

https://projecao.br/centraldocumentos/download/3065. Acesso em: 12 set. 2018.

PPC. Projeto Pedagógico do curso de Serviço Social. Faculdade Projeção de Guará. Guará (DF), 2016b. Disponível em: https://projecao.br/centraldocumentos/download/3051. Acesso em: 12 set. 2018.

PPC. Projeto Pedagógico do curso de Serviço Social. Centro Universitário Ages UNIAGES. Salvador, 2016c [impresso].

PPC. Projeto Pedagógico do curso de Serviço Social. Faculdade de Ciências e Tecnologias do Maranhão - FACEMA. Caxias (MA), 2009. Disponível em: http://facema.edu.br/wpcontent/uploads/2011/01/PPC-SERVI\%C3\%87O-SOCIAL.pdf. Acesso em: 12 set. 2018.

PPC. Projeto Pedagógico do curso de Serviço Social. Faculdade Metropolitana da Amazônia - FAMAZ. Belém, 2017. Disponível em: http://www.famaz.edu.br/portal/wpcontent/uploads/2017/11/PPC-Servi\%C3\%A7o-Social1.pdf. Acesso em: 12 set. 2018.

VILLARDI, M. L., CYRINO, E. G., BERBEL, N. A. N. A metodologia da problematização no ensino em saúde: suas etapas e possibilidades. In: A problematização em educação em saúde: percepções dos professores tutores e alunos. São Paulo: Editora UNESP; São Paulo: Cultura Acadêmica, 2015, pp. 45-52.

SANTOS, Cláudia Mônica dos. Na prática a teoria é outra? Mitos e dilemas na relação entre teoria, prática, instrumentos e técnicas no Serviço Social. Rio de Janeiro: Lumem Juris, 2011.

SANTOS, Cláudia Mônica dos. Os instrumentos e técnicas: mitos e dilemas na formação profissional do assistente social no Brasil. Tese (doutorado). Universidade Federal do Rio de Janeiro. Escola de Serviço Social. Programa de Pós-graduação em Serviço Social. Rio de Janeiro: UFRJ, 2006.

\section{Everton Melo da Silva}

Assistente social. Doutorando em Serviço Social pela UFAL. Mestre em Serviço Social pela UFAL. Membro do Grupo de Estudos e Pesquisas Marxistas (GEPEM/UFS). Bolsista CAPES. 